\title{
O regime de Comodato como empecilho aos direitos dos quilombolas
}

\author{
Sandro Silva ${ }^{1}$ \\ Universidade Federal do Espírito Santo
}

Resumo: O artigo descreve as relações entre as empresas de commodities e os quilombolas no norte do estado do Espírito Santo. A partir do cenário do conflito étnico e territorial, proponho descrever como as relações entre capital e quilombolas se mantém com base na reprodução das condições de subalternidade. Lanço mão da análise de dispositivos desenvolvidos pelas empresas de commodities para acomodar os conflitos enquanto se colocam como mediadores no acesso a direitos, antes apenas oferecidos pelo Estado.

Palavras-chave: Quilombos; Sapê do Norte; Espírito Santo [estado]; Commodities.

${ }^{1}$ Professor do PGCS/PPDIR. 


\section{Atos de governo}

Nos anos 1980, Gerson Camata, eleito governador e prometendo se distanciar da Ditadura Militar, montou uma proposta governamental para "interiorizar o desenvolvimento", reforçando secretarias de sua administração com quadros oriundos da universidade e militantes de "tendência de esquerda" que não encontravam espaço durante o regime ditatorial. A Secretaria de Agricultura (SEAG) foi um destes espaços de inovação administrativa de seu governo. (Valadão, 1999) Até este momento, o governo do estado começava a desenvolver uma Reforma Agrária baseando-se nas diretrizes do Plano Nacional de Reforma Agrária que se mostrou ineficaz, especialmente pela oposição da bancada ruralista no Congresso.

Dentre as iniciativas capixabas destacavam-se a compra de "terras improdutivas", a indenização de latifundiários e o assentamento de famílias de camponeses que haviam sido expropriadas, o que agradou as elites locais, devido a oportunidade de se capitalizarem, e a Igreja Católica que havia se colocado como crítica do latifúndio, mas contras as "invasões"-(Tribuna do Cricaré, 1987) No entanto, a diminuta quantidade de famílias assentadas, para as projeções do governo, levou a críticas aos planos estaduais de Reforma Agrária e a reorganização de ações de ocupações em vários municípios no norte capixaba. Outro aspecto central em meu argumento é que o governo federal no período da Ditadura Militar havia investido na "Revolução Verde" e o governo estadual capixaba beneficiou as empresas de monocultivo de eucalipto com subvenções fiscais e terras oferecidas a preços simbólicos no norte do estado. A construção da imagem da "terra desocupada" e da "baixa produtividade das propriedades", preconizadas pelas agências econômicas capixabas, favoreceu a sobreposição do projeto de commodities sobre a ocupação camponesa nesta região, autorizando política e juridicamente o latifúndio.

\section{A instituição da diferença}

Para contornar a "crise no campo" enfrentada na região do norte capixaba, Valadão (1999) argumenta que o governo em tela elaborou um plano administrativo baseado no regime de comodato, onde as famílias de camponeses sem terra assinariam contratos temporários de ocupação da terra e se beneficiariam de políticas especiais de fomento agrícola. Esta forma de administrar o crescente conflito no campo foi aceita pela Igreja Católica e Sindicato Rural de São Mateus, mas duramente criticada por outras agências como o recém criado MST e a CPT. No reduto eleitoral de Camata a pequena propriedade era uma realidade desde início do século XX com a imigração europeia, mantendo uma relação estreita entre a imagem de uma comunidade camponesa e a igreja católica, mas no norte capixaba vigorava o regime de latifúndios centrados na criação bovina e na presença da maior população negra do estado, originada do período escravista.

Para a Igreja Católica e o Sindicato Rural de São Mateus o comodato significava a possibilidade de "conquista" pela via legal, mantendo planos diferenciados de negociação mediante a manutenção do conflito e o avanço sobre as estruturas de concorrência política dentro do estado. Esta era a via institucional que 
agradava os fazendeiros católicos, o governo católico e os camponeses que não queriam romper as relações de reciprocidade locais. Para o MST e a CPT, a autonomia do camponês deveria ser a prioridade das políticas públicas e por isso recusavam as ações de governo daqueles diferentes atores que eram vistas como acomodações políticas às exigências empresariais e uma forma de paternalismo que poderia criar "currais eleitorais". Tratava-se de romper a dependência dos camponeses com os latifundiários e com a Igreja e mostrar que a pequena propriedade e o projeto socialista eram viáveis social e economicamente, ou seja, a imposição de uma nova divisão do mundo social e a introdução de capitais sociais distintos daqueles existentes e reconhecidos como tais (Bourdieu, 2003; 1997). Ao fim de cerca de cinco anos pouco mais de cem famílias haviam sido contempladas com sítios de em média 5 hectares por família como na definição dos assentamentos do projeto de colonização do estado de início do século XX (Colbari, 1997). Isso mobilizou as críticas do MST e forças ainda mais radicais na direção contrária da via "institucional".

O avanço do MST no norte capixaba, como mostra Valadão (Ibid.), fez surgir outras formas de administração da terra mediante a administração dos sujeitos coletivos "trabalhador rural sem-terra", que passou ritualisticamente da "onda de invasões" a sujeito que figura na burocracia e rotinas de planejamento de estado. Uma transição no âmbito da administração dos corpos também se estabeleceu. Da propriedade coletiva, aspiração socialista dos líderes do MST, passou-se à constituição do cooperativismo agrícola - como forma de manter a "luta pela terra" como modelo social, mas também de criar condições de competitividade econômica da terra e manter a fronteiras identitária com o latifúndio e o trabalho assalariado. Esta transição não fez desaparecer as diferenças entre os assentados que aderiram no primeiro momento à "luta pela terra", mas buscavam autonomia em relação às formas definidas pela agência MST de acesso e manutenção da terra. Em meio à panóplia de soluções técnicas, pareceres e mobilizações tanto do estado quanto das agências que defendiam os "sem terra", havia um embate não evidenciado, silencioso e fragmentado em jogo que provocará desdobramentos inusitados no cenário contemporâneo recente.

Parte significativa da categoria dos "trabalhadores rurais" que estavam mobilizados pelo Sindicato Rural de São Mateus era composto de trabalhadores migrantes dos estados de Minas Gerais e Bahia, recrutados durante os primeiros dez anos de operação das empresas de celulose para o trabalho pesado no campo, uma vez que projetos nacionalistas como o Proálcool, plantio de eucalipto para celulose, aumento das pastagens para gado bovino e o petróleo- fizeram parte da "carteira de investimentos estatais neste momento na região. Mas, outros sujeitos também emergiram deste contexto de expropriação fundiária, cuja prerrogativa era também remodelar as identificações camponesas.

\section{Outras identificações}

Nem todos os “trabalhadores sem-terra” aderiram à mobilização unilateral ou foram incorporados às agendas de assentamento estatais, especialmente se considerarmos a via da identificação preconizada pelas agências mediadoras ou governamentais que requeriam fidelidade identitária ao projeto de administração do espaço e do tempo camponês. Isto me conduz a palavra "servidão", apresentada no resumo, um tanto "fora de moda", mas que sugere a violência simbólica seja em relação às relações de mando dos fazendeiros em relação a este gru- 
po de trabalhadores, seja em relação às organizações sindicais ou outras que definiam o acesso a direitos a partir de determinada identificação. Para tornar operacional esta categoria é preciso considerar que o regime jurídico que determinou o fim da escravização da população afrodescendente não colocou fim às condições sociais e econômicas de sua manutenção, incluindo aí as propriedades morais atribuída aos agentes em suas relações.

A parcela significativa de sujeitos, anônima nos idos de 1980, tinha relações sociais distintas com a terra e com os demais agentes políticos governamentais ou não. Nos casos analisados, eles faziam parte de relações de posse e propriedade antiguíssimas e formas de mediação estranhas à dicotomização [assentados/fazendeiros] que se requeria para a inscrição nos "movimentos sociais". Ademais, muitos não se consideravam "sem terra" e, pelo contrário, desenvolviam relações complexas com as formas de ocupação do espaço seja pela via do trabalho parcelar, seja por meio de redes de parentesco e casamento que promoviam a colocação dos novos casais ou de amigos. Destaca-se também as relações de grilagem que estavam implícitas no trabalho parcelar para os fazendeiros da região, haja vista os relatos que associam o acesso a novas terras à favores e qualidades morais de certos fazendeiros. Não são poucos os relatos de troca de glebas de terra por um montante de trabalho na derrubada, destocamento, plantio e colheita de roças variadas (Ferreira, 2002, 2009; Silva, 2012).

Estas terras eram mantidas como parcela do patrimônio familiar ancestral e incluíam-se na própria constituição da história de grupos extensos e cujas parentelas ocupavam de forma peculiar o Sapê do Norte. A história pessoal e dos grupos estava imbricada com a história de constituição destes sítios, sua aquisição, os percursos de sua negociação e, mais recentemente, à sua perda nas disputas do agronegócio que levaram a comercialização das terras, que "não tinham valor", como classificam os quilombolas. A definição da terra sem valor tem suas implicações na constituição das identificações e nas relações de interação local. Por agora assinalo que estas relações podem ser entendidas como hierárquicas, no sentido de Bourdieu (2003), ou seja, elas constituem um sistema de posições que estão relacionadas por habitus específicos. Como pretendo demonstrar mais adiante, estas posições são explicitadas em momentos como a quebra de determinadas relações de confiança, quando acordos tácitos são quebrados por outra lógica.

Os patronímicos familiares eram referidos aos sítios, configurando relações de parentesco e definindo a memória compartilhada sobre os nomes dos lugares como córregos e portos à beira rio. Uma característica fundamental na definição destas outras identificações camponesas eram os limites das propriedades e a definição da fronteira entre elas. Enquanto a proposta de assentamentos vistas acima preconizava o modelo da família nuclear e deixava pouco espaço à mobilidade do grupo de parentes, os sítios desta outra parcela de camponeses tinha como aspecto singular a definição da família extensa como sujeito coletivo desta ocupação. A literatura sobre comunidades rurais quase sempre cai em um comunalismo plano ao definir a relação entre posse e propriedades das terras, no entanto os modelos locais apontam relações complexas e muitas vezes conflituosa em relação à posse e propriedade da terra.

Tais conflitos remontam à construção de fronteiras sociais entre diferentes grupos definidos como "fazendeiros" ou "fortes" que se opunham aos "fracos" e "pequenos proprietários". Adotando diferentes temporalidades, os narradores quilombolas chegam à camada da memória que é definida como fundamental e 
uma espécie de origem comum para os "fracos". A escravização como o "tempo do cativeiro" se sobrepõe à todos os demais tempos do conflito e reconduz o espaço social para outro patamar de compreensão. Para a parcela mobilizada politicamente em torno da identificação negra e quilombola, este é o tempo/espaço fundamental de onde emergem todos as práticas que violam seus direitos.

Ademais, eles se apresentam aqui como sujeitos "negros" deslocando o debate de "classe" para o de "raça" e da "política trabalhista" para a "política cultural", que era marginal na organização simbólica das agências como o STRSM e o MST. Esta nova inscrição identitária, que pude acompanhar nas entrevistas e nos documentos produzidos pela organização Grupo de União e Consciência Negra [GRUCON], se organizou por volta de meados dos anos 1980, chegando a público pela mobilização coletiva pela defesa de uma "cultura negra" e do processo de resistência dos afrodescendentes (Silva, 2012). A despeito do debate de classe, a [re]ruraliação passa a concentrar os esforços de várias agências políticas e religiosas. Nas margens destes dois fluxos, a raça retoma o cenário do conflito social através de associações com designação histórica ligada à escravização como o Grupo de União e Consciência Negra e a Associação Afrocultural Benedito Meia Légua. Tais identidades racializadas redefiniram outras fronteiras que se sobrepuseram no espaço rural contemporâneo, demonstrando que o contexto de intervenção estatal e das agências como CPT e Diocese não eram suficientes para abranger outros atores que estavam presentes. Pelo contrário, alguns destes agentes são percebidos como "a causa" da discriminação de famílias negras do campo e supressão da sua cultura religiosa, como o Bispo Neri que perseguiu os Cabuleiros no início do século XX (Aguiar, 2001).

A onda de esbulho que varreu o Sapê do Norte entre 1970 e 1990 reduziu o tamanho das posses dos quilombolas e originou uma nova forma de organização social: a Comunidade. Ela passou a ser o resultado da pastoral religiosa (CPT, CPN), mas também de exercício de classificação estatal responsável pela redução do universo social à vida em comunidade passível de administração e aplicação de regimes de governo e princípios de classificação. (Bourdieu, 1997; 2003) A comunidade torna-se o caminho por onde é construída uma nova territorialização no Sapê do Norte, agora marcado pela relação constante com as agências públicas e privadas, mas também um espaço de controle intensificado e disputado entre diversos atores.

Os institutos agrícolas capixabas desenvolveram atividades distintas nestas comunidades que iam de cursos de fabricação de produtos de higiene a técnicas agrícolas para melhorar a produtividade e oferta de produtos. Os pleitos do movimento quilombola capixaba reproduzem este discurso governamental e reivindicam a regularização dos territórios, indicando de forma fragmentada as comunidades a serem identificadas e regulamentadas. O governo federal, através do INCRA, procura, a partir de um saber judicializado, circunscrever uma ou mais comunidades em um "território tradicional" que represente minimamente as condições anteriores de produção e reprodução social, imaginadas para o mundo camponês. Em meio a estas ações a empresa de Celulose desenvolveu vários "programas sociais" que tiveram objetivos diversos, como pretendo acompanhar em seguida. 


\section{O Comodato como organização do território e dos sujeitos}

Trato agora da proposta empresarial do ramo das commodities de celulose para estabelecer o regime de comodato entre os quilombolas e como são desenvolvidas as estratégias de reorganizar os quilombolas. Procurei compreender e comparar o conjunto de enunciados e práticas dispersas por documentos oficiais da empresa que orientam este "princípio de divisão" que ao mesmo tempo que pretende disciplinar os conflitos em torno do território, provoca deslocamentos nos processos de identificação dos sujeitos e agências (Bourdieu, 2003).

A primeira vista, considero que as ofertas disponíveis de inscrição do direito à terra - incluindo aí a representação da população que tem este direito -, formam um cenário de conflito e concorrência entre agentes estatais e privados pelo direito de impor a sua visão de mundo social. Neste sentido, o que faz com que a proposta da empresa de celulose e do INCRA sejam diferentes? Por que alguns dos representantes dos quilombolas rejeitam a proposta da empresa e se empenham em defender a proposta governamental? Enfim, sobre que bases a empresa oferece uma alternativa para acomodar os conflitos em torno dos direitos territoriais?

A reação dos quilombolas, especialmente os membros da Comissão Quilombola do Sapê do Norte, sublinharam a [re]produção da subordinação por meio do que eles denominaram de "migalhas", originando uma fronteira entre o projeto da empresa e aqueles que eles definem como o seu. Recorrendo a outros eventos no tempo me detive nas práticas e formas de constituição destas ações tanto da Firma como do INCRA - , como uma forma colonial, sublinhando a produção de um governo da diferença a partir da organização da sociedade pois, sob a ótica do mercado das commodities, propõem-se a administração do espaço e das formas de diferenciação social. Embora a proposta da empresa de celulose seja bastante judicializada, são os bastidores desta proposta que me interessam aqui como expressão de ações de governo e definição de produção de identificações. (Foucault, 1999)

Isto porque tais ações são caracterizadas como marginais e ao mesmo tempo o centro do conflito pois denunciam a porosidade das fronteiras entre diferentes agências do Estado e das empresas privadas. A imagem do "contrato", de um papal escrito e assinado, surge como um artefato político que mobiliza os mercados de bens simbólicos em concorrência, mobilizando também planos diferentes de identificação em relação aos sujeitos que concorrem no campo político pelos diferentes capitais (Bourdieu, 2003).

Ao propor um contrato de comodato a Empresa de celulose pretende chamar para si o lugar que se imagina de um Estado clientelista, reforçando a máxima foucaultiana de que não é através da lei que se governa, mas através de dispositivos de saber-poder que tem por característica constituir identificações no momento mesmo em que é criado (Foucault, 1999). O que quero dizer é que o conflito pelos territórios quilombolas revela um plano de concorrência entre agentes que, na disputa pelos diferentes capitais disponíveis, criaram um campo político regional.

A titulação coletiva, como prevê os dispositivos jurídicos quilombolas (CF, Art. 68 e Decreto 4887/2003), não estavam previstos no conjunto de ações da Empresa de celulose, de maneira que ela lançou mão de uma estratégia ímpar nos cenários das empresas de commodities capixabas para solucionar o "confli- 
to”, mas não muito estranha às ações do governo capixaba que já haviam sido implantadas na região, como vimos. A proposta de um regime de Comodato remete à discussão para pelo menos dois planos que se interligam: em primeiro lugar procura administrar os conflitos locais com os quilombolas e em segundo lugar procura pacificar/domesticar as tensões internacionais onde se inserem as commodities e onde outras racionalidades são cobradas para a certificação de produtos, como a "sustentabilidade" de que tratarei em seguida.

O que chamarei de "dispositivos de saber empresariais" representa um aparato de procedimentos por meio dos quais a Empresa de celulose mantém interações com os quilombolas, incluindo aí saberes técnicos e atitudes morais em relação ao governo do cotidiano quilombola.

$\mathrm{O}$ projeto do comodato, apresentado de forma um tanto secreta pela empresa, traz em resumo a seguinte redação: atribui a uma relação entre a empresa "legítima proprietária e possuidora" e os quilombolas a criação de contatos individuais entre proprietários para a cessão de parcelas de terra "apenas" para "culturas de ciclo rápido" com financiamento oriundo de parcerias não explicitadas; a administração dos plantio será feita entre empresa e associações; o prazo é de no máximo dez anos, sendo renovável caso haja interesse das "partes" [sic]; a associação se responsabiliza pelos danos causados às plantações e pelos equipamentos; as terras doadas não podem ser ocupadas com outras formas de trabalho [parceria, parcelar] e culturas a não ser aquelas definidas no contrato; a não devolução do bem em comodato implica as penas legais e multas aos quilombolas; ceder à empresa o direito de fazer vistorias; criar um cadastro onde os quilombolas informem a relação dos associados com a terra [se já possui terra, composição familiar e experiência com a terra]; manter um cadastro dos associados, bem como informar a empresa a situação dos associados em relação à "participação" na vida da associação; prestar conta das movimentações financeiras e arcar com despesas fiscais e impostos.

Não basta, no entanto, criar leis se não produzir sujeitos capazes de as cumpri-las e defende-las publicamente. As formas de introdução de novos capitais no mercado da concorrência pela representação quilombola é uma ótima estratégia apresentada pela empresa. Em meio aos dispositivos jurídicos do comodato e sua apresentação pública como sinal de civilidade empresarial, a construção de "lideranças", se mostra uma técnica sutil engendrada por agentes da empresa, mas cujos efeitos práticos são agravados pela disputa de poder no interior dos planos de representação quilombola. Muito raramente este "ponto de partida" é tomado como objeto de estudo em nossas análises, o que denota a naturalização da inscrição dos sujeitos e suas posições no espaço social. Para termos uma ideia da situação destes estudos, basta dizer que muitos grupos étnicos têm seu processo de etnogênese ligado à existência de empreendimentos privados, bem como a continuidade das fronteiras ligadas às várias nuances destas relações específicas com o capital.

Sentidos de circulação política como "governança" e outras características "substantivas" e "subjetivas”, como "participação", "organização" fazem parte de um amplo leque de categorias empregadas na atualidade pelas empresas e empreendimentos para produzir mediações com os grupos por eles afetadas, bem como se inserir em outros territórios econômicos. Ainda que seja o estado brasileiro e suas agências a criarem situações de identificação de grupos étnicos, a instrumentalização desta nominação e dos seus aparatos de agenciamento, estão muitas vezes limítrofes às ações de estado, se estendendo a agências gover- 
namentais locais como subproduto de suas ações de governo. As condições de produção desta relação talvez nos mostre que "é preciso interessar-se não pelos produtos culturais oferecidos no mercado de bens, mas pelas operações de seus usuários; é mister ocupar-se com as 'maneiras diferentes de marcar socialmente o desvio operado num dado pela prática”'(Certeau, 2000; 13)

Instrumentos de certificação, avaliação de desempenho, posições nos mercados globais, stake-holders, dentre outros, fazem parte de cenários de composição de capitais específicos que estão em jogo na definição das relações entre as empresas, o que elas fazem, o que dizem que fazem e a imagem que querem de si no mercado. Assim, por exemplo há uma série de instrumentos de certificação que levam em seu conjunto de análises a audição da "comunidade" envolvida em uma determinada situação. O sistema ISO é um destes instrumentos que medem várias capacidades de produtos, serviços e mesmo de pessoas. Segundo a ABNT a necessidade de certificação se deve ao fato de que "certificar um produto ou serviço significa comprovar junto ao mercado e aos clientes que a organização possui um sistema de fabricação controlado, garantindo a confecção de produtos ou a execução dos serviços de acordo com normas específicas, garantindo sua diferenciação face aos concorrentes" (ABNT, 2011). Neste sentido, a certificação tem a ver com universos muitas vezes distantes daqueles em que ele teve origem, de maneira que o que se certifica é um objeto produzido em nível global para atender um consumidor também global.

Acontece que as empresas procuram também produzir seus certificados segundo critérios defendidos por elas como adequados às suas condições de produção. Uma empresa que produz petróleo não vai querer ser avaliada por uma norma que regulamenta frutas, por considerar não só que frutas e petróleo são coisas distintas, mas que o mercado a que eles interessam também é diverso. Nesta operação singela, as condições de produção de petróleo e frutas, ou seja, as relações de trabalho, são colocadas em outro patamar de avaliação, pois eles devem atender a normas específicas. Embora as normas sejam diferentes elas atendem a uma ideia fundamentalmente igual, ou seja, padronizar a vida social e produzir sobre ela uma ação de governo. Assim é que não só os procedimentos são padronizados, mas também, as matérias-primas e a própria natureza é estandardizada.

Procuro em seguida descrever de maneira breve como a empresa de celulose, considerando o longo histórico de interação social, busca determinar sua relação com os quilombolas estabelecendo uma "leitura" das conjunturas históricas em relação às políticas públicas - especialmente a titulação quilombola -, para definir o escopo de sua ação. Buscando estandardizar suas ações por meio de mediações ela define, em decorrência disto, identificações em proveito dos seus processos produtivos. Ou seja, através do processo de aprendizado histórico das relações com os quilombolas, no caso estudado, a empresa mimetizou as formas de tutela estatal e pretende transformá-las em uma forma de mediação com estas populações ${ }^{2}$.

E aqui volto à questão da etnogênese de grupos tradicionais. A manutenção do conflito entre empresas e aqueles grupos tem recebido pouca atenção, exatamente porque estes são pensados de maneira estática em relação às condições de produção de suas identificações. Nos dedicamos a mostrar que estes

${ }^{2}$ Por tutela me refiro a discussão feita por Leitão e Araújo (2002) e Lima (1995) que evidenciam a tutela não somente como um dispositivo jurídico, mas cognitivo. 
grupos são dinâmicos, não são isolados e não estão parados no tempo, mas fazemos isso recorrendo à uma perspectiva interna dos grupos, preterindo o agenciamento mais amplo de categorias em outros planos de produção de identificações. Quando os "nativos" não estão incluídos nestes processos centrais de produção de identificações, os consideramos como "invizibilização". Pois bem, os processos de certificação, particulares ou estatais, produzem também "visibilidades" que muitas vezes são aquelas que constam nas tomadas de decisão das agências de estado. Por exemplo, no caso de relatórios anuais percebemos a utilização da expressão "partes interessadas" para a empresa se referir aqueles universos de atores mais amplos como agentes governamentais, ONG's, sociedade civil e grupos étnicos. Ademais, o investimento social dos "parceiros" na construção ou reconhecimento da identidade quilombola não pode ser preterido deste conjunto de "produções" como condição de definição das fronteiras tanto dos grupos quanto dos "parceiros".

\section{Governança: história, raça e território}

Um dos aspectos chave para compreendermos a produção de uma relação tutelar no interior do negócio da Empresa de celulose é acompanhar como ela produz sua relação de autoridade com os quilombolas. Trata-se, como propõe Bourdieu, de não se interrogar sobre "o que é", mas quem define os "produtores da mensagem” simbólica (Bourdieu, 1997;120). Esta relação deriva de duas características: a primeira delas evidenciada pela produção da linguagem socialmente aceita sobre a "sustentabilidade" e a segunda originada da percepção dos quilombolas sobre a empresa como parte do campo político que eles classificam com representações sobre "força" e "poder". Farei uma apresentação sumária das duas perspectivas, tomando como minha etnografia no Sapê do Norte e a análise de um relatório público da empresa de 2007, 2009 e 2010, bem como o parecer da consultoria externa por ela contratada para efeito do seu processo de certificação internacional. Além das referências à Bourdieu, especialmente aquelas ligadas a suas reflexões sobre a análise econômica e produtivista do poder e a dominação simbólica, procuro aqui compreender os processos de construção de uma linguagem territorializada da colonialidade que produz sujeitos a partir de sua inscrição em categorias de pertencimento associadas a lógicas de concorrência no mercado de bens simbólicos.

Até 2007 a empresa de Celulose mantinha uma relação truculenta com parte dos movimentos sociais, e de busca da tutela com outros. Herdeira de uma visão autoritária da nação, oriunda da gênese política e administrativa da Ditadura Militar, a principal foco de ação da empresa até meados da década de 1990 foi ignorar as demandas por direitos dos grupos que tiveram suas ocupações violadas. O desenvolvimento econômico apregoado pela empresa tinha o papel missionário de salvar as populações colocadas à margem pelos processos econômicos anteriores. Assim, aqueles que se propuseram a enfrentamentos com a empresa foram classificados como marginais ao processo de integração, uma espécie de mão de obra desqualificada sujeita às oscilações do mercado de trabalho imposta por sua atividade.

A imagem que a empresa mantinha daqueles afetados por suas atividades era a de "comunidade carente", sobre as quais ela exibia estatísticas de apoio financeiro e "para melhorar a gestão dos investimentos sociais da Empresa foi criado o Instituto Aracruz Bem de Raiz, cujo objetivo é promover o desenvolvi- 
mento comunitário sustentável a partir do fortalecimento do capital humano, social e econômico, priorizando comunidades carentes nas áreas de atuação da Aracruz" (Aracruz Celulose, 2007; 24).

A empresa já desenvolvia "programas sociais", por meio dos quais exercia uma relação de "parceria" com os quilombolas. O "programa bons vizinhos", por exemplo, se constituía de apoio na preparação dos plantios quilombolas com horas de trator e palestras sobre meio ambiente e conservação. Mais recentemente, o programa "vigilantes florestal" emprega quilombolas e outros grupos na observação sistemática de distúrbios nas plantações de eucalipto que podem ser de caráter de furto, danos ou incêndios - uma vigilância interna, uma vez que são as mulheres e filhos dos quilombolas, os contratados preferenciais. Outras iniciativas envolvem a recuperação de maquinários considerados pelos quilombolas como "tradicionais", como as casas de farinha, e outras inovações na renda doméstica, como a apicultura. Em todos estes casos as iniciativas financeiras são acompanhadas de uma forma pedagógica de governo que valoriza a "formação" pessoal em valores "cidadãos" de maneira que os quilombolas sejam convertidos de "comunidades carentes" em "parceiros" e possam compreender as atividades da empresa. Por meio de cursos e formações didáticas o espaço das relações sociais pretende ser alterado e produzir efeitos no desenvolvimento da organização do espaço dos plantios de eucalipto. A proposta é diminuir os conflitos mudando as relações entre empresa e os quilombolas, reduzindo assim as fronteiras, vistas como fonte de conflito, e ampliar a competição com as demais agências de mediação com os quilombolas. Mas, a "posição social" da empresa é definida, pelos seus próprios responsáveis, de forma ambígua entre uma iniciativa estritamente privada e a possibilidade de "parceria" governamental.

Ou seja, o "problema quilombola" que era visto como um "problema territorial" e de "carência da região" e foi convertido como parte de estratégias de ordenamento do espaço - não somente físico, mas sobretudo simbólico -, e gestão de capitais públicos e privados, passando a integrar uma máquina de governo. Na prática o objetivo do novo grupo econômico é instalar-se nas comunidades quilombolas e exercer sua governança de dentro da comunidade e não mais provocando situações de enfrentamento público como fazia a empresa de Celulose. Se a população é um "problema", soluções de governo são aplicadas à ela, tais como "políticas públicas e articulação entre os diversos agentes locais" mediante mecanismos de "participação/decisão" de atores previamente selecionados para "fazer a história": sociedade civil, poder público, conselho comunitário, empresas do grupo Votorantim e realizadores.

Mas, os efeitos da concorrência no interior das agências de estado, além da mudança da linguagem da governança, levaram a Empresa de celulose a se reposicionar, ao menos em nível público, em relação ao "conflito". Em parte do relatório de "sustentabilidade" de 2009 a empresa redefine o seu "Relacionamento com comunidades negras". Evocando a história, ela inicialmente mostra que houve uma leitura contrária à CF de 1988 que transformou os "descendentes de escravos fugidos das senzalas (os quilombolas), o direito de receberem a escritura das terras que até então ocupavam (onde no passado haviam-se agrupado formando comunidades, os chamados quilombos)" (Fibría, 2009; 56. Grifo meu). O relatório indica que ao invés de acatar o que dizia a lei o "governo editou um decreto (n. 4.887) que deu novo significado à palavra quilombo e alterou bastante o que tinha sido estabelecido pela Constituição [pois este] estabeleceu que seriam considerados quilombolas os grupos raciais que se dissessem des- 
cendentes de negros, segundo critérios de auto-atribuição [definindo] que suas terras seriam aquelas utilizadas para a garantia de sua reprodução física, social, econômica e cultural, levando em consideração critérios de territorialidade e indicações daqueles que se considerassem remanescentes das comunidades dos quilombos, e não mais aquelas terras que estivessem sob sua posse desde a abolição da escravatura até 8 de outubro de 1988”. (Idem, Idem. grifei)

O que causou surpresa, no referido relatório, foi que "com isso, passaram a poder ser consideradas quilombolas outras terras, além daquelas já ocupadas desde 1888, criando-se novos direitos de propriedade que conflitam diretamente com os direitos de outras pessoas, jurídicas ou físicas, no campo e até nas cidades" inclusive "outros 9.606 mil hectares pertencentes a proprietários rurais, inclusive negros que não se consideram quilombolas" (Idem, Idem. grifei). Após situar o "problema” o relatório se posiciona em relação a ele argumentando que não questiona o direito de propriedade destas comunidades e que deseja manter relações "boa vizinhança", mas teme pela sua imagem uma vez que "qualquer oposição da nossa Empresa pode ser erradamente interpretada como racismo ou como negação de direitos tradicionais das comunidades. Temos como vizinhos essas comunidades muito pobres, que possuem poucas opções de renda e veem em ser reconhecidas como quilombolas uma oportunidade de prosperar, em vista das promessas com que o decreto 4.887 lhes acenam." (Ide, grifei)

Como se vê, o ingresso da empresa no jogo de posições do campo político é marcado pela incorporação/imposição de várias linguagens. O que me fez citar este relatório é o movimento de revelar/ocultar partes do jogo ao mesmo tempo em que ao reforçar as disposições incorporadas pelos atores - o ato jurídico dos quilombos -, sublima as formas de imposição da violência simbólica que pretendem definir como regras de validade no campo. A Justiça aparece como o lugar neutro, "que vai tomar uma decisão", enquanto a empresa "aguarda" e aguardando "a estratégia da Fibría é fortalecer a relação com essas comunidades, por meio de engajamentos e investimentos sociais, de forma a promover a sua inclusão social, [como] envolver essas comunidades no negócio da Fibría, seja criando relações de emprego direto e indireto ou fomentando a atividade florestal no modelo de agrofloresta"(Ibid.)

A denegação de seu lugar no jogo de posições, recusando as relações entre o passado e esquecendo a história, marca, como diz Bourdieu, da violência simbólica sobre um determinado campo social, remete os atores a outras formas de “adesão" mediante a construção de outros planos de "adesão" ao novo princípio de divisão do mundo social. (Bourdieu, 1997). Esta visão do mundo leva a Firma a diagnosticar-se como apenas um dos atores presentes nas áreas ocupadas por essas comunidades, o que a leva a dialogar "com outros atores públicos e privados para buscar uma solução global, de médio e de longo prazo, que melhore a condição de vida dessas e de outras comunidades carentes vizinhas promovendo um processo de desenvolvimento social e econômico que melhore suas condições de vida" (Fibría, 2009; 57. grifei).

\section{Considerações finais}

Se na década de 1980 a Aracruz Celulose foi acusada pelos agentes pastorais da terra, dos sindicatos e GRUCON de expulsar os quilombolas para as favelas da cidade, a nova correlação de forças no campo político levou a empresa 
de celulose a inaugurar uma gestão dos pobres por meio de saberes e práticas que lembram o confinamento humano assistido com recursos extraídos das políticas federais de combate à pobreza e dos bancos de desenvolvimento sociais.

A implantação do comodato foi proposta tendo como base local a criação de uma associação dos moradores, figura jurídica que passaria a responder pelo contrato, mas não pela administração dos recursos. Sugiro que tais iniciativas não são novas, mas denotam a organização de um campo político no Sapê do Norte como parte de um longo processo de institucionalização da presença estatal que preenche espaços sociais e político das trajetórias das populações rurais e suas lutas por direitos na região em questão.

Bourdieu (2003) adverte que a direção do exercício da dominação simbólica é importante na compreensão da organização do espaço social, ou seja, das relações entre as posições dos atores. A pretensa repartição do capital cultural empresarial, traduzido na linguagem prática dos quilombolas - terra e dinheiro para as plantações -, mas sobretudo o contato físico e a palavra trocada, pode reforçar os esquemas de dominação construídos no campo político em questão. Considerando as experiências de mobilização das décadas de 1980 e 1990, como vimos, marcadas pela ocupação do espaço público, mas também pela organização da classe camponesa em torno de diversos projetos, pode ser responsável pela criação de um conjunto de práticas e disposições que associam a "reunião" não como um ato, mas como um princípio de percepção legítimo e legitimador do espaço político. Os critérios e sucesso do princípio de divisão desenvolvidos pela CPT e MST no campo político foram a reunião e a mobilização que derivaram - mas ao mesmo tempo legitimavam do processo de "conscientização". Hoje, os quilombolas acreditam que agora a empresa "vai até eles, fazem reunião e mostram sua cara”, denunciando esquemas espaciais hierárquicos que procuram "reduzir a distância", reconhecida e incorporada nas relações e, ao mesmo, tempo inculcar novos capitais necessários à manutenção das relações de poder. A empresa busca aqueles grupos e indivíduos que ela considera organizados o suficiente para propagar as suas ideias, mas não o suficiente para resistir-lhe. $\mathrm{O}$ deslocamento "para baixo" da parafernália de técnicos da empresa é mistificado pelos rituais do poder como deslocamento horizontal, na linhagem das "partes", empregada no campo como as reuniões e as visitas à sede da empresa. Embora as reuniões e confrontos ocorram com frequência nas reuniões com a Comissão Quilombola, o encontro com o Outro visto como superior, muda o posicionamento dos agentes, especialmente porque as regras do combate e confronto são alteradas pela percepção da nova posição no campo, ou seja, não se está mais olhando para o lado, mas para onde se quer chegar, seja lá onde for.

O objetivo deste artigo foi descrever que ações tutelares não são produzidas apenas por agências de Estado, mas podem se originar em agências privadas, se reposicionarmos nossa perspectiva das relações de poder e à combinação das condições de objetivação da organização do poder tutelar. Procurei perceber como a empresa de celulose, considerando o longo histórico de interação social, determina sua relação com os quilombolas estabeleceu uma "leitura" das conjunturas históricas em relação às políticas públicas - especialmente a "titulação coletiva" -, para definir o escopo de sua ação. Buscando estandardizar suas ações por meio de mediações ela define, em decorrência disto, identificações em proveito dos seus processos produtivos. Ou seja, através do processo de aprendizado histórico das relações com os quilombolas, no caso estudado, a empresa 
mimetizou as formas de tutela estatal e pretende transformá-las em uma forma de mediação com estas populações.

\section{Referências}

AGUIAR. M. Os últimos Zumbis. Brasil-Cultura. Porto Seguro, 2001.

ALMEIDA, Alfredo Wagner Berno de. Os quilombos e as novas etnias. Revista Palmares, Brasília, 2000.

ALMEIDA, Alfredo Wagner Berno de. Terras de preto, terras de santo, terras de índio - uso comum e conflito in Castro e Hébette (orgs.). Belém: Caderno NEA 10, Gráfica e editora universitária UFPA, 1989.

APPADURAI, Arjun. Dead Certainty: Ethnic Violence in the Era of Globalization. Public Culture 10(2): 225-247, 1998.

Aracruz Celulose S/A. Relatório Anual e de Sustentabilidade. 2007

Aracruz Celulose S/A. Relatório Anual e de Sustentabilidade. 2008

ARRUTI, José Maurício Andion. Mocambo: antropologia e história do processo de formação quilombola. Edusc/ANPOCS. 2006.

ASSIES, Willem. HOEKEMA, Andre, VAN DER HAAR, Gemma. The Challenge of Diversity: Indigenous Peoples and Reform of the State in Latin America. Thela Thesis Amsterdam, 2000.

Audiência Pública. Ministério Público Federal. São Mateus, 2008. Vídeo/cor. Dur. $125 \mathrm{~min}$.

BARTH, Fredrik. Etnicidade e o conceito de cultura, Antropolítica. Niterói. n. 19. 2005.

BENSA, Alban. "Da micro-história a uma antropologia crítica”. In: REVEL (Org.). Jogos de Escalas. Rio de Janeiro: FGV, 1998 (pp. 39-76).

BOLTANSKI, Luc. "La Dennonciation”. Actes de la Recherche en Sciences Sociales, (51), pp. 03-40, 1984

BOURDIEU, P. 1997. A ilusão biográfica. In : AMADO, J. \& FERREIRA, M. M (orgs.). Usos e abusos da história oral. Rio de Janeiro : Fundação Getúlio Vargas.

BOURDIEU, P. O poder simbólico. Bertrand Brasil, Rio de Janeiro. 2003.

COHEN, Anthony P. (ed.). Signifying identities: anthropological perspectives on boundaries and contested values. London, New York: Routledge, 1999. 
CUNHA, Olívia Maria Gomes da. Quase-cidadão: histórias e antropologias da pósemancipação no Brasil. Rio de Janeiro, FGV, 2007.

DAS, Veena. "Fronteiras, violência e o trabalho do tempo: alguns temas wittgensteinianos”. Revista Brasileira de Ciências Sociais, v. 14, n. 40, jun. 1999

ERIKSEN, Thomas Hylland. Ethinicity and nationalism. Pluto Press, London/Chicago. Illinois.1991.

FERREIRA, S. R. B. "Donos do lugar": a territorialidade quilombola do Sapê do Norte - ES. Tese de Doutorado apresentada ao Programa de Pós-Graduação em Geografia da Universidade Federal Fluminense, como requisito para obtenção do grau de Doutora em Geografia. 2009.

FERREIRA, S. R. B. Da fartura à escassez: a agroindústria de celulose e o fim de territórios comunais no extremo Norte do Espírito Santo. Dissertação de Mestrado da autora em Geografia Humana. São Paulo, USP, 2002.

Fibría. Relatório Anual e de Sustentabilidade. 2009

Fibría. Relatório Anual e de Sustentabilidade. 2010

FOUCAULT, Michael. A verdade e as formas jurídicas. NAU Ed. Rio de Janeiro, 1999. FOUCAULT, Michel. Deux essais sur le sujet et le pouvoir. in Hubert Dreyfus e Paul Rabinow, Michel Foucault. Un parcours philosophique, Paris, Gallimard, 1984, pp. 297-321.

GOMES, Flávio dos Santos. A hidra e os pântanos. Polis/Unesp. São Paulo, 2005 .

HOUTZAGER, Peter. Os últimos cidadãos. Ed. Globo. Rio de Janeiro, 2004.

LIMA, Antonio Carlos de Sousa. Um grande cerco de paz. Vozes, Rio de Janeiro. 1995

MATTOS, H. \& GOMES, A. C. Sobre apropriações e circularidades: Memória do cativeiro e política cultural na Era Vargas. LABHOI, S/D. Mimeo.

Ministério do Meio Ambiente. Temas Conflituosos Relacionados à Expansão da Base Florestal Plantada e Definição de Estratégias para Minimização dos Conflitos Identificados. Brasília, 2005.

O'DWYER, Eliane Cantarino. Os quilombos e as fronteiras da antropologia. ANTROPOLÍTICA. Niterói. EdUFF. N. 19, 2005.

OLIVEIRA, Osvaldo Martins. O projeto político do território negro de retiro e suas lutas pela titulação das terras. Tese doutorado. Universidade Federal de Santa Catarina programa de pós-graduação em antropologia social. Santa Catarina, 2005 .

POLANYI, Karl. A Grande Transformação as origens de nossa época. Rio de Janeiro, Editora Campus. 1980. 
PRESIDÊNCIA DA REPÚBLICA. Decreto 4887/2003. Brasília, 2003.

SILVA, Sandro José da. Do fundo daqui: Luta política e identidade quilombola no Espírito Santo. Tese de doutorado. PPGA-UFF. Niterói. 2012.

Tribuna do Cricaré. Jornal impresso. Várias edições. São Mateus.

VALADÃO, Vanda de Aguiar. Assentamentos e sem terra, a importância dos mediadores. Edufes, Vitória, 1999. 